\title{
WestVirginiaUniversity
}

THE RESEARCH REPOSITORY @ WVU

Graduate Theses, Dissertations, and Problem Reports

2010

\section{From Bigfoot in the backyard to ghosts in the attic: Predictors of paranormal belief}

Jeff Tranguch

West Virginia University

Follow this and additional works at: https://researchrepository.wvu.edu/etd

\section{Recommended Citation}

Tranguch, Jeff, "From Bigfoot in the backyard to ghosts in the attic: Predictors of paranormal belief" (2010). Graduate Theses, Dissertations, and Problem Reports. 855.

https://researchrepository.wvu.edu/etd/855

This Thesis is protected by copyright and/or related rights. It has been brought to you by the The Research Repository @ WVU with permission from the rights-holder(s). You are free to use this Thesis in any way that is permitted by the copyright and related rights legislation that applies to your use. For other uses you must obtain permission from the rights-holder(s) directly, unless additional rights are indicated by a Creative Commons license in the record and/ or on the work itself. This Thesis has been accepted for inclusion in WVU Graduate Theses, Dissertations, and Problem Reports collection by an authorized administrator of The Research Repository @ WVU. For more information, please contact researchrepository@mail.wvu.edu. 
From Bigfoot in the Backyard to Ghosts in the Attic:

Predictors of Paranormal Belief

\author{
Jeff Tranguch
}

Thesis submitted to the

Eberly College of Arts and Sciences at West Virginia University in partial fulfillment of the requirements

for the degree of

\author{
Master of Arts \\ in \\ Applied Social Research
}

Melissa Latimer, Ph.D., Chair

Corey Colyer, Ph.D.

Ron Althouse, Ph.D.

Division of Sociology and Anthropology

Morgantown, WV

2010

Keywords: Religion; Religiosity; Paranormal Belief 


\section{ABSTRACT \\ From Bigfoot in the Backyard to Ghosts in the Attic: Predictors of Paranormal Belief}

\section{Jeff Tranguch}

Previous research on the social predictors of paranormal belief is contradictive and unclear. Depending on which author you read, one theory is better at explaining why individuals accept belief in paranormal phenomena. This problem most likely is the result of weak sample sizes and an inconsistency in defining and measuring the paranormal. This thesis incorporates data from the 2005 Baylor Religion Survey which is one of the largest, most recent data sets assessing paranormal belief. Three predominant theories within the literature are tested. Findings lend support to the marginalization theory claiming that individuals who are marginalized from society tend to hold more paranormal beliefs, both religious and non-religious. Significant support is also given for the small step hypothesis suggesting that the more religious paranormal beliefs an individual holds, the more likely he or she is to hold non-religious paranormal beliefs. Furthermore, support is given to the functional alternative hypothesis proposing that individuals who do not have a religious identity (religious "nones") are more likely to profess belief in the non-religious paranormal. 


\section{CONTENTS}

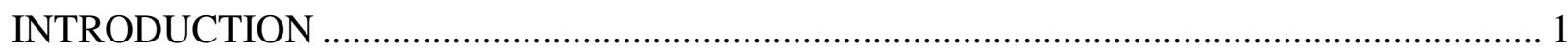

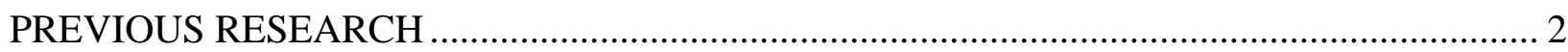

Measurement of the Paranormal ...................................................................................... 2

Demographic Variables ......................................................................................... 5

Religious Beliefs vs. Paranormal Beliefs..................................................................... 5

Paranormal Beliefs as an Alternative to Religious Beliefs ........................................... 6

Experimentation with the Paranormal .............................................................................. 7

Belief in the Existence of Evil and Paranormal Belief ........................................................ 7

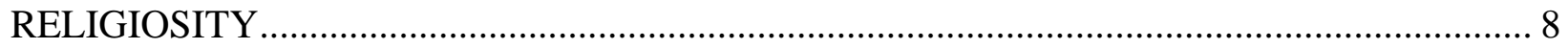

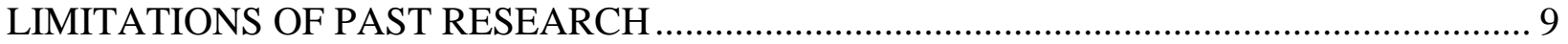

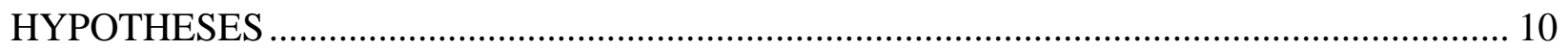

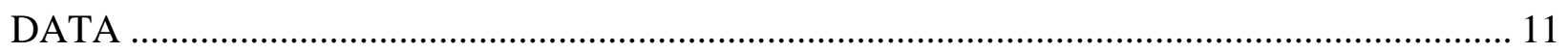

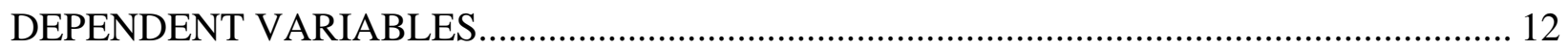

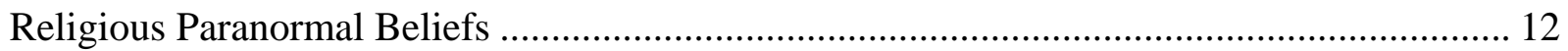

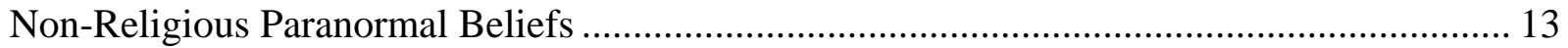

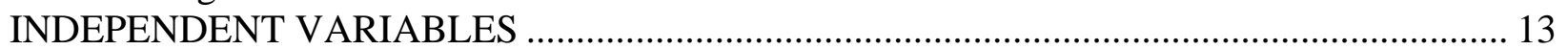

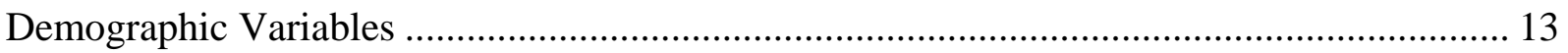

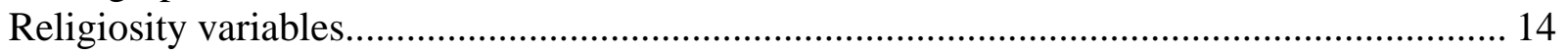

Table 1Percentages for Demographic Variables................................................................ 15

Table 2A: Percentages for Religiosity Variables................................................................. 16

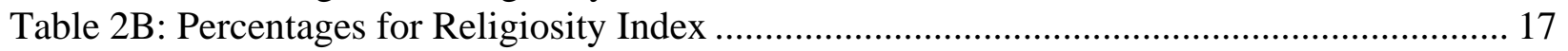

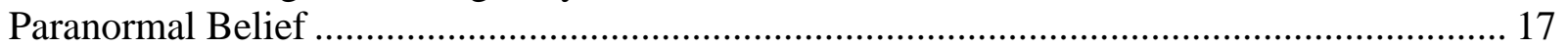

Table 3A: Percentages for Religious Paranormal Belief Items .............................................. 18

Table 3B: Percentages for Religious Paranormal Belief Index .............................................. 19

Table 4A: Percentages for Non-Religious Paranormal Belief Items ........................................ 20

Table 4B: Percentages for Non-Religious Paranormal Belief Index ........................................ 21

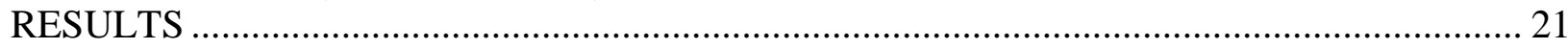

TABLE 5 OLS Regression Predicting Religious Paranormal Belief ....................................... 22

TABLE 6 OLS Regression Predicting Non-Religious Paranormal Belief ................................ 24

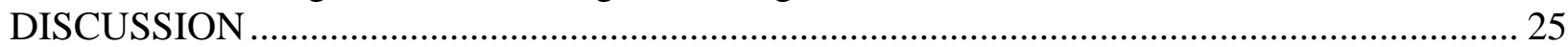

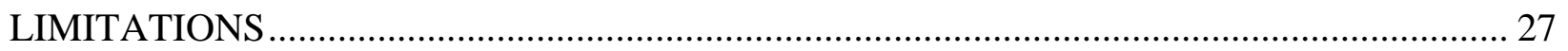

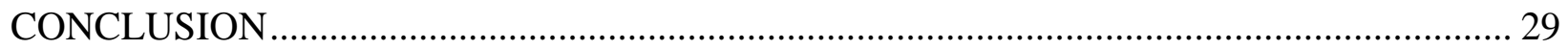

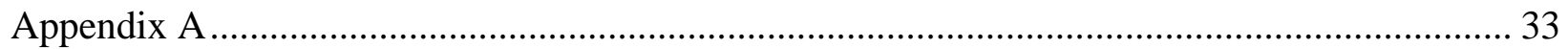

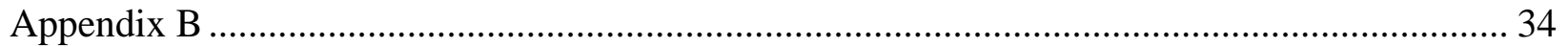

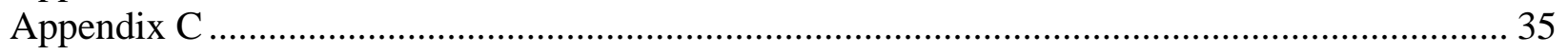

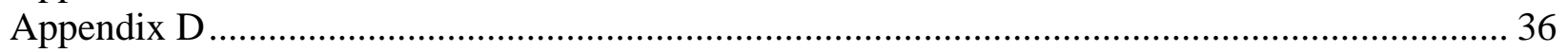

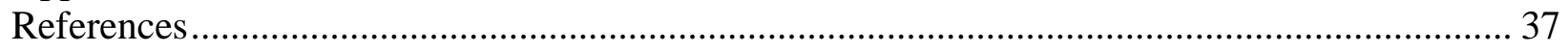




\section{INTRODUCTION}

According to a recent Gallup poll, approximately three out of every four Americans believe in the existence of at least one form of paranormal phenomena such as haunted houses, ESP, or Bigfoot (Gallup 2005). This statistic may or may not be influenced by the outburst of television programs within the past decade. You can turn on the television just about any day of the week and expect to find at least one program promoting the existence of paranormal phenomena. Since 2001, a total of 22 shows have surfaced on basic cable with nine emerging since 2008 at the time research on this thesis began. ${ }^{1}$ Even with this recent outburst of paranormal programming on television, media portrayal of the paranormal is nothing new. Several other television programs have aired over the years supporting the existence of paranormal phenomena including Unsolved Mysteries, The X-Files, and Crossing Over with John Edwards. Aside from television, thousands of newspapers are published every day with horoscopes and stories covering anything from Bigfoot to UFOs.

The media encourages widespread belief in the paranormal, but to what effect do the media have on influencing others to adopt these beliefs? Even with all the emerging paranormal programming on cable television today, 2005 Gallup poll data suggest a decline in belief when compared to data collected in 2001. Belief in ESP has fallen (50\% vs. 41\%) along with clairvoyance ( $32 \%$ vs. $26 \%$ ), ghosts ( $38 \%$ vs. $36 \%$ ), communication with the dead ( $28 \%$ vs. $21 \%$ ), and the channeling of spirits through human bodies (15\% vs. $9 \%$ ). This discovery is quite interesting considering that existing research has found that individuals who profess belief in paranormal phenomena often cite the media as the reason for their beliefs (Alcock 1981). Sparks, Sparks, and Gray (1995) also found that a respondent's tendency to believe in UFOs was greater after viewing a program supporting their existence. This claim that the media influences individuals in adopting paranormal beliefs is also supported by Sparks, Nelson, and Campbell (1997) who suggest that the viewing of paranormal television programs is positively correlated with paranormal belief.

Various definitions of what constitutes something being "paranormal" have been proposed over the years. However, within these definitions, there seems to be one common theme; these phenomena challenge or lie outside our knowledge of the physical world and our scientific understanding. Peltzer (2003) defines the paranormal as phenomena which defy the basic

\footnotetext{
${ }^{1}$ For a list of these television programs please see Appendix A.
} 
limiting principles of science. Thalbourne (1982) argues the paranormal to be the set of processes which lie outside of our human ability to understand. Based on these definitions, ghosts, horoscopes, Tarot cards, Bigfoot, and UFO's could be classified as paranormal simply because each of these concepts rely completely on individual belief since they cannot be proven to exist through modern principles of science.

Technically, conventional religious belief also qualifies as paranormal belief. That is, we lack definitive evidence for the existence of angels, demons, the devil, etc. Belief in these entities rests entirely on faith alone. However, regardless of whether they exist or not, some beliefs are more socially acceptable than others. According to Mencken, Bader, and Kim (2009) concepts of God, Heaven and Hell, the resurrection of Jesus, and the Virgin birth are viewed as traditional beliefs within the Christian faith. Because the majority of the United States is Christian (roughly 79\% according to the 2005 Baylor Religion Survey), these concepts are viewed as acceptable both from a religious and societal viewpoint since they lie within the dominant belief system within Christianity. On the other hand, paranormal beliefs such as ESP or UFOs lie outside of mainstream religious dogma and are seen as less acceptable through the eyes of the church and society.

This thesis is builds upon the work of Mencken et al 2009 in an attempt to verify their results using the same data set from the 2005 Baylor Religion Survey. The overall goal of this thesis is to identify which variables predict belief in the religious and non-religious paranormal. Prior research on this topic is limited, contradictive, and unclear as to the effect and relationship specific variables have on paranormal belief. Depending on which author you believe, one theory is better than the other at predicting belief. Much of the confusion is caused by poor sample sizes and inconsistency in defining the paranormal. This analysis hopes to clarify those social variables which drive individuals to accept paranormal beliefs.

\section{PREVIOUS RESEARCH}

\section{Measurement of the Paranormal}

Depending on the range of paranormal beliefs considered, several scales have been designed in the past, all of which have the same goal of assessing belief in the paranormal. Some are larger and more encompassing than others, and each contain their own idea of what "paranormal" actually entails. One of the smaller types of measurement used to asses these beliefs is known as the sheep-goat scale. While this scale contains statements assessing belief in 
other forms of the paranormal, traditionally it is most commonly used for measuring belief in the existence of extrasensory perception (ESP), or the ability to acquire knowledge without previous knowledge or use of the senses. It contains 15 questions which prompt the respondent to choose one of three possible answers (True/Uncertain/False). Eleven items measure belief in ESP and telepathy, two measure belief in life after death and communication with the dead, and the remaining questions concern the drawing out of ESP within a laboratory environment. These scales were formulated to differentiate between those individuals who are sheep (those who profess strong belief in the existence of ESP) from those who are goats (those who report little or no belief in the existence of ESP).

Other researchers argue that paranormal belief encompasses more than just parapsychological phenomena such as belief in UFOs, demons, astrology, Bigfoot, and other types of religious, superstitious, and supernatural beliefs. One of the more customary scales used in assessing a wider range of belief in the paranormal is Tobacyk's Paranormal Belief Scale which is comprised of 26 items covering questions on religious belief, superstition, spiritualism, psi belief, extraordinary life forms, precognition, and witchcraft. For each of the 26 responses, respondents are asked to choose their answer based on a 7-point Likert scale ranging from strongly disagree to strongly agree with an uncertain category in between. Over the years, this method of measurement has been used in several different research projects in its entirety or with some minor revisions (see Aarino and Lindeman 2007; Peltzer 2003; Tam \& Shiah 2004).

\section{Dominant Theories within Paranormal Research}

Over the years, researchers have developed several theories in an attempt to explain what factors influence individuals to accept paranormal beliefs. The marginalization theory, sometimes referred to as deprivation theory, hypothesizes that individuals who are marginalized from the rest of society due to lack of power or status are more likely to hold paranormal beliefs. These marginalized individuals include women, minorities, the poorly educated, and those with low annual incomes. Due to their lack of status or power, these individuals tend to accept alternative beliefs and reject traditional belief systems as a means of explaining why certain events or crises occur within their lifetime. Aarino and Lindeman (2007) support this idea showing that paranormal believers and “double” believers (those who accept both religious and paranormal claims) were individuals who faced slightly more negative events in their lifetime compared to those participants who identified as skeptics. It may be possible that these 
individuals hold these beliefs because they view some concepts of the paranormal such as astrology or tarot cards offer some explanation or guidance in their lives.

Closely related to the marginalization argument is Hirschi’s (1969) social bond theory. This theory hypothesizes that individuals who adhere closely with social and cultural norms will exhibit less deviant behavior. As I mentioned earlier, religious beliefs are deemed more socially acceptable because they are part of the dominant belief system within the United States. It is the non-religious beliefs that are stigmatized and feared by many, especially those tied closely to the church and its teachings. Because of this, individuals who possess power or status in society (e.g. politicians) should view non-religious paranormal beliefs as unattractive and threatening to their self-image and avoid these beliefs altogether. At face value, this argument ties loosely into the marginalization/deprivation argument since it suggests a negative association between religious and paranormal beliefs. For all intents and purposes, it argues that individuals who possess status within society should profess little to no belief in the paranormal. Based on these two theories, I predict for paranormal belief, both religious and non-religious, to be strongest among those individuals who are young, non-white, less educated, female, and those who have low annual incomes.

Contrary to the marginalization/deprivation argument is the small-step hypothesis which suggests a positive relationship between religious and paranormal beliefs. In essence, people who hold conventional religious beliefs are more likely to accept paranormal beliefs. Rice (2003) suggests that if a person believes in devils and angels, it is only a small step for that individual to also believe in ghosts and aliens. This makes logical sense considering that both types of beliefs rely completely on individual faith and cannot be proven to exist through modern techniques of science.

When talking about the small-step argument, it is important to remember that some steps may be "smaller" than others. For instance, one could argue that it is a smaller step for someone to belief in demons and haunted houses rather than angels and tarot cards. Because I believe the marginalization theory better predicts paranormal belief, and the fact that I will be controlling for religiosity, I predict a negative relationship between religious and non-religious paranormal beliefs. Religiosity should act as a filter separating one type of believer from another.

The functional alternative hypothesis has also been applied within this type of research as a means of explaining belief in the paranormal. This theory states that it is an individual's lack of 
religious beliefs that drives them to adopt alternative belief systems that are usually magical or supernatural (see Emmons and Sobal 1981). In other words, it could be that these individuals adopt certain belief systems as a means of explaining life events because they lack a religious identity or religious beliefs. This relates back to the argument I made in a previous paragraph. Religion and religious beliefs offer some explanation and guidance for individuals looking for answers to life's most challenging questions. On the other hand, non-religious beliefs may offer some guidance. It seems quite logical for someone who does not identify with any formal religion to seek and adopt non-religious paranormal beliefs. Essentially, the individual is not under any pressure by the church or other religious peers to adhere to any religious ideas and is free to adopt whichever beliefs he or she pleases. Because this theory suggests a positive relationship between religious “nones” and paranormal belief, I will control for religious "nones” within this analysis in order to test this argument. I expect for "nones” to report stronger belief in the non-religious paranormal.

\section{Demographic Variables}

Overall, the main goal of paranormal research for sociologists has been to establish what factors influence an individual to accept paranormal beliefs. Sex seems to be only variable that has been proven to predict belief in the paranormal consistently. Past research has shown women tend to score higher than men in scales of paranormal beliefs (Irwin 1985). Women are also more likely than men to report paranormal experiences (Fox 1992; MacDonald 1995). However, men have professed stronger belief in UFO’s (Clarke 1991) and the Loch Ness Monster (Tobacyk and Milford 1983). It has also been suggested that women are more religious and spiritual than men overall (Mears and Ellison 2002). Mencken et al (2009) suggest that women may see spirituality as an element of femininity, thus causing them to accept paranormal beliefs on a larger scale than males.

\section{$\underline{\text { Religious Beliefs vs. Paranormal Beliefs }}$}

Previous studies have also examined the relationship between religious and paranormal beliefs. Sheils and Berg (1977) presented a sample of college students with various statements aimed at measuring religious and paranormal belief. Statements such as "I believe heaven and hell are actual places” measured "religious belief”, while "paranormal belief” was measured by statements such as "I think it is possible for people to communicate directly from mind to mind." Their findings showed greater religious belief was negatively correlated with belief in psychic 
events. However, using the same methodology and a different college sample, Tobacyk and Milford (1983) found that high religious belief was positively correlated with belief in precognition, witchcraft, and negatively with spiritualism.

One of the more famous and widely cited studies was conducted by Alan Orenstein in 2002. In order to measure religious belief, Orenstein asked respondents were asked if they believed in Heaven, Hell, angels, God, life after death, and God's presence. Paranormal belief was calculated by asking respondents to state belief in ESP, psychic powers, déjà vu, astrology, communication with the dead, and reincarnation. His analysis suggests that religious and paranormal beliefs are positively correlated, while church attendance and paranormal belief are negatively correlated. In response to these findings, McKinnon (2003), using the same data, discovered that religious and paranormal beliefs are positively correlated, but only for those who do not attend church regularly. McKinnon suggests that it may be likely that paranormal beliefs act as a substitute for religious involvement for people who hold traditional religious beliefs.

Building on this research, Mencken et al (2009) compared differences between traditional Christian beliefs, which they define as belief in God, Jesus as the son of God, heaven, and hell and paranormal beliefs or what they call "New Age" beliefs were measured by belief in astrologers, palm-readers, tarot card readers, fortune tellers, psychics, communication with the dead, haunted houses, UFO’s, Bigfoot, and the Loch Ness Monster. Results from their analyses propose that strong belief in conventional Christian beliefs is negatively correlated with belief in the New Age paranormal. However, once demographic and religiosity measures were controlled for, a strong positive relationship emerged between the two, thus giving some support to the small-step hypothesis. Support for the marginalization theory was also yielded suggesting that individuals who are older, white, and better educated are significantly less likely to report strong paranormal beliefs.

\section{$\underline{\text { Paranormal Beliefs as an Alternative to Religious Beliefs }}$}

Other researchers have taken a different approach in assessing paranormal belief. A 1981

study conducted by Emmons and Sobal attempted to discover if paranormal beliefs served as an alternative to mainstream religious beliefs. Belief of the paranormal was divided into categories which they identified as religious paranormal beliefs and non-religious paranormal beliefs. Respondents were asked to simply state a yes or no response to belief in ghosts, the Loch Ness Monster, Bigfoot, ESP, witches, déjà vu, precognition, astrology, angels, devils, life after death, 
and clairvoyance. The religious paranormal were measured by positive responses to angels, devils, and life after death. Belief in the non-religious paranormal was shown through positive responses in the remaining phenomena. Results confirmed their hypothesis suggesting that respondents who do not identify with a religious affiliation (religious “nones”) reported lower than average belief in the religious paranormal and much higher levels of belief in the nonreligious paranormal. This finding coincides with the work of Bainbridge and Stark (1981), yet contradicts the findings of Orenstein (2002) and Mencken et al (2009).

\section{Experimentation with the Paranormal}

Some researchers, rather than simply measuring belief in certain phenomena, have opted to examine individual experimentation with the paranormal. Some of us may know someone who has consulted a psychic, read their horoscope, or dabbled with a Ouija board. Seeing that not a great deal of research had been published on this topic, Mencken, Bader, and Stark (2008) sought to discover the relationship between conventional Christian beliefs and experimentation with the paranormal. Using data from the 2005 Baylor survey, their findings suggest that individuals who are firm believers in Christianity are just as likely as those who are not to experiment with the paranormal. In fact, those who did not attend church frequently but still hold conventional Christian beliefs were the most likely to experiment with the paranormal. Additional findings also show some support for the marginalization hypothesis with females reporting more paranormal experiences while older, wealthier respondents reported the least amount of paranormal experiences.

\section{Belief in the Existence of Evil and Paranormal Belief}

There are those researchers who will argue that a belief in the existence of evil forces (i.e. the devil, demons, etc.) has a significant impact on an individual's attitude toward particular behaviors and ideas, including the paranormal. Bader, Baker, and Mencken (unpublished) examined those individuals who believe that there is a constant "spiritual battle" occurring in reality between God and Satan. Results imply a positive relationship to exist between belief in evil supernatural forces (Satan, demons, Hell) and non-Christian paranormal beliefs (UFOs, haunted houses). In fact, belief in evil forces proved to be the second most powerful predictor of paranormal belief next to church attendance, which surprisingly had an opposite effect on belief. 


\section{RELIGIOSITY}

Berger and Luckmann (1966:11) claim that churches are among the most important organizations for maintaining a "monopoly over all ultimate definitions of reality." Based on this assumption, one would guess that the more one is exposed to church teachings and practices, the less paranormal beliefs one would hold. This is where the concept of religiosity may play an important role in understanding paranormal belief. Throughout the various research projects conducted on the paranormal, religiosity has been measured in different ways such as church attendance, religious identity (theologically liberal, Bible-believing, Evangelical, Fundamentalist, etc.), or how often one prays. In the past, certain forms of religiosity have proven to be helpful in understanding paranormal belief. Aarino and Lindeman (2007) found that higher religiosity was negatively associated with paranormal beliefs. Utilizing church attendance, Orenstein (2002) discovered that frequent religious attendance was negatively correlated with paranormal belief. In response to his findings, Orenstein suggests that religious participation is one of the strongest predictors of paranormal belief. Similarly, Mencken, et al (2009) also discovered that both church attendance and biblical literalism have a significant negative effect on paranormal beliefs.

Based on the assumptions in the previous paragraph, I predict for religiosity to be the strongest predictor of paranormal belief, both religious and non-religious. Being highly religious exposes individuals to environments where certain norms and standards are established. In being exposed to these environments, individuals become familiar with what beliefs and practices are more acceptable than others. Attending church is just one way for individuals to be exposed to such environments. Church attendance alone has proven to be a strong negative predictor of paranormal belief (McKinnon 2003; Orenstein 2002). Individuals who attend church as least weekly are exposed to others who hold similar beliefs to their own, and much like young men in a fraternity house, these individuals should be least likely to engage in activities or accept beliefs that are incongruent with the specific norms established by the institution.

However, attending church on a consistent basis is not the only way to assess religiosity. Church attendance may not even be the best indicator for religiosity. As Smith (1998: 20) states, people who claim to attend church regularly may be apathetic religiously, yet they still attend in order to achieve the status they think goes along with being a church-going citizen of the 
community. Because of this, I believe a wider range of variables should be included in this analysis in order to attain a more accurate indicator of an individual’s religiosity.

\section{LIMITATIONS OF PAST RESEARCH}

There are certainly some reasons as to why the literature on this topic is confusing and contradictive. In general, there are few studies which incorporate samples large enough to generalize to the national population. Those that are large enough either incorporate data which are outdated (Emmons and Sobal 1981) or non-representative of the United States (Orenstein 2002). Because of this, researchers have not been able to generalize results to the national population. Rice (2003) agrees that data limitations are to blame for inconsistent conclusions about social predictors of paranormal belief. He adds that although many studies incorporate large samples, they are limited because they include only a small battery of questions assessing paranormal belief. It is important for research such as this to be conducted in order to start building the framework for definitive conclusions. This thesis tries to make and advancement in the study of paranormal belief by utilizing, random national sample data consisting of over 1,700 respondents in its analysis.

Research such as this is also important because it could contribute to argument of whether or not individuals are substituting paranormal beliefs for religious beliefs. Emmons and Sobal (1981) discovered that individuals who do not identify with any religious affiliation ("nones”) reported lower belief in religious paranormal phenomena and higher belief in the non-religious paranormal. If this analysis supports research suggesting that religious “nones” are more likely to adopt beliefs which lie out of mainstream religion, it could lend support to the argument of the secularization of America.

Additionally, this study is devised with the logic to test that those individuals who identify as highly religious should not hold beliefs which lie outside of traditional church teachings. Likewise, those who report weak religiosity should be the most likely to report weak belief in religious paranormal phenomena and strong belief in the non-religious paranormal. For example, highly religious respondents should be least likely to believe in non-religious paranormal phenomena such as UFOs because traditional church teachings state that man and all other forms of life were created here on earth. If someone were to believe in UFOs, hypothetically, they would believe in the existence of other life forms outside of our planet. These beliefs are at odds with each other because they conflict with traditional religious beliefs. 
If the data suggest that both the highly religious and the non-religious are holding more and more of these non-religious paranormal beliefs, this could mean that America is slowly becoming a secularized nation. That is, if the religious are just as likely as others to accept belief in nonreligious beliefs, it could mean that these beliefs are slowly becoming acceptable within society. With the fascination of the paranormal in the media in the past few years, this may be what is happening.

Lastly, existing research also lacks an extensive measure on religiosity. The overwhelming majority of research includes anywhere from 1-3 variables aimed at capturing individual religiosity. This analysis will utilize six variables aimed at assessing religiosity. Due to the lack of large samples, along with weak indicators of religiosity, I believe researchers have undermeasured the power religiosity may hold in helping explain paranormal belief. This research should help fill the void that exists within this literature because these data are taken from one of the largest nationally representative data sets assessing paranormal belief.

\section{HYPOTHESES}

Previous literature proposes that a highly religious person should not condone beliefs and activities outside of social norms. This explanation ties into Hirschi's social bond theory where individuals with a strong adherence to social and cultural norms will exhibit less deviant behavior. A highly religious person exposed to the activities and beliefs of their institution should see unconventional beliefs as a threat to their religious identity. Holding religious beliefs but not practicing the faith through activities such as attending church allows the individual to become less exposed to religious tension (Glendinning 2006; McKinnon 2003); Stark and Bainbridge 1985). As a result, these individuals may seek to involve themselves in activities outside their faith (Mencken, Bader, and Stark 2008).

Based on the information provided above, I hypothesize the following:

1. Religiosity is positively associated with belief in the religious paranormal and negatively with belief in the non-religious paranormal.

2. Religiosity will be the strongest predictor of both Christian and non-Christian paranormal beliefs.

3. Individuals who identify as religious "nones" will be more likely than individuals with some religious identity to believe in the non-religious paranormal. 
4. Based on the assumptions of the marginality hypothesis, individuals who are female, younger, poorly educated (high school or less), have a low SEI, and are non-white will report higher belief in the non-religious paranormal.

5. Religious paranormal beliefs and non-religious paranormal beliefs are negatively associated with one another when controlling for religiosity.

\section{DATA}

Data are taken from the 2005 Baylor Religion Survey which was developed by a team of researchers at Baylor University including Rodney Stark, Christopher Bader, Carson Mencken, Byron Johnson, Paul Froese, Jerry Park, and Kevin Dougherty. Funded by the John Templeton Foundation, the survey is part of a three wave study with the 2005 survey serving as the first wave. Data were gathered by the Gallup Organization using a mixed-mode sampling design which consisted of telephone and self-administered mailed surveys conducted from October 7, 2005 to November 1, 2005. Initially, 1,002 interviews were completed over the phone with a national sample of the general population of adults 18 or older. The sample was drawn from telephone using random digit dialing spanning households across the continental United States. Interviews were conducted with the person in the household age 18 or older and who had the most recent birthday. After the initial call was completed, two call-backs followed. Once each interview was completed, respondents were then asked to take part in another study being conducted by the Gallup Organization which examined the beliefs and values of Americans. In exchange for their participation, each respondent was given $\$ 5.00$. Once consent was given by the respondent, a mailing address was requested by Gallup. 660 of the initial 1,002 respondents agreed to participate. Of the 660 respondents contacted by telephone, 603 agreed to give their mailing address.

In addition to those 603 respondents, Gallup mailed 2000 questionnaires to its national random digit dial database. Originally 2,603 questionnaires had been sent across the country. A total of 1,721 surveys were completed and returned to Gallup which yields a response rate of 46.5 percent. $^{2}$

The Baylor Survey is appropriate for this research because it contains many more items that operationalize religiosity other than church attendance such as "How often do you pray?”, “How often do you say grace?”, “How often do you read the Bible or Koran?”, “How often do

\footnotetext{
${ }^{2}$ Response rate represents the total sample contacted.
} 
you participate in religious activities such as Bible study or Sunday school?” These questions provide superior measure of religiosity than church attendance alone.

Baylor's national sample makes these data generalizable to the United States population of adults. As mentioned in a previous section, the bulk of the literature draws upon unrepresentative samples. In utilizing these data, I hope to verify results similar to Mencken et al (2009).

\section{DEPENDENT VARIABLES}

\section{$\underline{\text { Religious Paranormal Beliefs }}$}

Emmons and Sobal (1981) compared differences between the religious (fundamentalist) paranormal and the non-religious paranormal suggesting that high belief in one category should result in low belief in the other. Because I define the paranormal as phenomena which lack physical, scientific evidence to support their existence, I operationalize in the same manner dividing the paranormal into two groups: religious paranormal beliefs and non-religious paranormal beliefs. In addition to these groups, my analysis incorporates more variables measuring paranormal belief and religiosity. In the paragraphs to follow, I elaborate which paranormal beliefs should be grouped into each category.

In the original Baylor survey, there were two sections assessing belief in paranormal phenomena. The first section assesses belief in some of the more common types of religious beliefs. The beliefs listed in this section are: God, heaven, hell, Satan, angels, demons, purgatory, Armageddon, the Rapture, and ghosts. It may seem odd that they would include ghosts in this category. However, one can argue that ghosts should be included here because the Christian religion believes in the Holy Ghost which is part of the Holy Trinity. Secondly, ghosts are mentioned within the New Testament, specifically within the Gospels of Matthew and Luke. ${ }^{3}$ Because of this, belief in ghosts may not be as stigmatized as some of the other beliefs such as astrology or UFOs. That is, because ghosts are recognized within the Christian religion, it is

\footnotetext{
${ }^{3}$ The Gospel of Matthew Chapter 14 Verse 2626 But when the disciples saw him walking on the sea, they were terrified, saying, "It is a ghost!"And they cried out in fear.

The Gospel of Luke Chapter 24 Verses 36-39 36 While they were talking about this, Jesus himself stood among them and said to them, "Peace be with you." 37 Thye were startled and terrified, and thought that they were seeing a ghost. 38 He said to them, "Why are you frightened, and why do doubts arise in your hearts? 39 Look at my hands and my feet; see that it is I myself. Touch me and see' for a ghost does not have flesh and bones as you see that I have."
} 
more acceptable for an individual to profess belief when compared to other types of nonreligious paranormal phenomena.

Non-Religious Paranormal Beliefs

Unlike the religious paranormal, the non-religious paranormal group contains phenomena which are slightly more stigmatized within society because they are not part of the dominant belief system. Again, these are beliefs that should be seen as risky and a threat to those individuals who hold higher status within society or profess high religiosity. This section of the Baylor survey was labeled The New Age which asked respondents to state their belief in alternative medicines, UFOs, Bigfoot, the Loch Ness Monster, astrology, haunted houses, tarot cards, palm readers, the ability to influence the physical world with the mind, the theory of Atlantis, and the ability for dreams to foresee future events.

An argument could be raised about the method through which I have classified these two groups, particularly in regards to my inclusion of haunted houses in the non-religious paranormal. Theoretically, it could be classified under either category. That is, if an individual believes in the existence of demons and ghosts, what would stop them from believing in the ability for houses to be haunted or vice versa? In other words, for someone to believe in haunted houses, one would think that it would be standard for them to also acknowledge the existence of demons and/or ghosts. Whichever way you look at it, there seems to be some relationship between specific sets of paranormal beliefs which would lend support for the small step theory. There may be a reason as to why previous research has found limited evidence supporting its claims. More specifically, it could be that the small step hypothesis is more successful in helping predict belief in certain types of paranormal phenomena over others. That is, it may be a “smaller” step for someone to believe in ghosts and haunted houses than for someone to go from believing in demons and ESP.

\section{INDEPENDENT VARIABLES}

\section{$\underline{\text { Demographic Variables }}$}

The demographic variables included in this analysis are age, sex, race, education, employment status, and income. Age will divided into four categories (18-30, 31-44, 45-64, 65 and older). This variable is coded in a manner that allows separation of individuals based on different life cycles they have experienced or will experience in the near future. For example, the 18-30 category represents those individuals who are high school graduates either entering the 
workforce or entering college or professional schools. The 31-44 category identifies those individuals who represent the labor force as well as those who may be starting families of their own. Category three (45-64) identify those individuals in the autumn of their lifetime preparing for retirement. Finally, category four (65 and older) represents those individuals who are entering retirement.

Sex was coded as a dummy variable representing females because the majority of research dictates that females are often more likely to profess belief in both types of the paranormal. Using similar logic and adhering to the marginality hypothesis, race was divided into two categories (white, other). Education was stratified on a 6 point range (less than high school, high school grad, some college, Jr. college, college graduate, postgraduate work/degree). This particular recode was coded by the Baylor research team and was included as part of the original data set obtained online from the Associate of Religion Data Archives. Each category represents a different educational experience and status in society which is the logic for using the recode as part of this analysis.

Employment status provides another measurement of marginality. Employment is normative and expected within society. Those who are not employed deviate from the mainstream. For these reasons, I have decided to include a dummy variable for unemployment ( 1 = unemployed; 0 = some form of employment).

The final demographic variable to be included in this analysis is annual household income. It is coded on a 5-point scale as follows: less than $\$ 20,000$, $\$ 20,001-\$ 35,000, \$ 35,001-\$ 50,000$, $\$ 50,001-\$ 100,000, \$ 100,001$ or more. As you can see, each one of these categories has a significant enough margin to differentiate various class units within society. Table 1 provides percentage distributions for these demographic variables.

\section{$\underline{\text { Religiosity variables }}$}

In coding the variables for religiosity, the main goal was to establish variables which would separate the highly religious individuals from those "go through the motions". The original 


\section{Table 1Percentages for Demographic Variables}

\begin{tabular}{|c|c|}
\hline VARIABLE & Percent \\
\hline \multicolumn{2}{|l|}{ Age } \\
\hline $18-30$ & $12.5 \%$ \\
\hline $31-44$ & $28.3 \%$ \\
\hline $45-64$ & $37.8 \%$ \\
\hline 65 and over & $21.3 \%$ \\
\hline \multicolumn{2}{|l|}{ Gender } \\
\hline Female & $47.1 \%$ \\
\hline Male & $52.9 \%$ \\
\hline \multicolumn{2}{|l|}{ Race } \\
\hline White & $13.6 \%$ \\
\hline Other & $84.5 \%$ \\
\hline \multicolumn{2}{|l|}{ Education } \\
\hline Less than High School & $8.3 \%$ \\
\hline High School Graduate & $18.2 \%$ \\
\hline Some College & $28.1 \%$ \\
\hline Jr. College & $10.5 \%$ \\
\hline College Graduate & $18.6 \%$ \\
\hline Postgraduate Work/Degree & $16.1 \%$ \\
\hline \multicolumn{2}{|l|}{ Income } \\
\hline Less than $\$ 20,000$ & $17.3 \%$ \\
\hline$\$ 20,001-\$ 35,000$ & $14.7 \%$ \\
\hline$\$ 35,001-\$ 50,000$ & $18.7 \%$ \\
\hline$\$ 50,001-\$ 100,000$ & $31.9 \%$ \\
\hline$\$ 100,001$ or more & $17.4 \%$ \\
\hline \multicolumn{2}{|l|}{ Employment } \\
\hline Unemployed & $27.1 \%$ \\
\hline Other & $72.9 \%$ \\
\hline
\end{tabular}

Baylor survey contained several variables measuring religiosity. A total of six variables measuring religiosity were used in this analysis with each one coded as a dummy variable in the 
following manner: church attendance (weekly or more), praying outside of normal worship hours (once a day or more), reading the bible or other religious texts outside of normal worship hours (weekly or more), Biblical literalism (the Bible means exactly what it says), how often a prayer of grace is offered at a meal (daily or more), and time spent participating in religious activities such as Bible study or Sunday School (3 or more times a month). Originally, the Bible study variable was coded on a scale from 1-4 (not at all, 1-2 times, 3-4 times, 5 or more). Although it is more appropriate to include individuals who participate in these activities at least five times a month or more, there were very few cases in which this occurred. Approximately $8 \%(n=132)$ of respondents in the data set satisfied this requirement. Including those who participate at least three times a month allows for concentration on a larger sample (approximately 19\%, $\mathrm{n}=327$ ), while still having a variable that is conservative enough to distinguish a person who is highly religious from someone who is not. Table 2A contains percentage scores for all six religiosity variables according to the dummy recodes.

Table 2A: Percentages for Religiosity Variables

\begin{tabular}{lc}
\hline \multicolumn{1}{c}{ ITEM } & PERCENT \\
\hline Attend church weekly or more & $30 \%$ \\
Pray once a day or more & $49 \%$ \\
Read the Bible at least weekly & $23 \%$ \\
Say a prayer of grace at least once a day & $31 \%$ \\
Attend Bible study or Sunday School at least & \\
three times a month. & $19 \%$ \\
Biblical literalism (Bible should be taken word-for-word) & $22 \%$
\end{tabular}

Appendix B contains the output for my religiosity index. In sum, all six variables for religiosity yield a Cronbach's alpha of .799 which satisfies the requirements for an accurate index. These variables are related to each other as a group and thus can be used as an accurate indicator of religiosity according to convention. A closer look reveals that the most significant variable within this index is how often one reads religious texts such as the Bible, Koran, or Torah which, if removed from this index, would yield a Cronbach's value of .748. This finding 
is quite fascinating considering the fact that the majority of research projects do not employ this variable.

According to the results, Biblical literalism is the least significant variable in building this index. One possible explanation is that this could be a weak indicator of religiosity when examined by itself, especially in terms of the other religiosity variables included in this index. In other words, all five remaining variables measure the extent to which someone is actively involved in a specific religious activity. Biblical literalism is concentrated more on someone's opinion rather than their actions which may be one reason it does not contribute to the index as much as the other religiosity variables do. Below are the percentage scores for the religiosity index.

\section{Table 2B: Percentages for Religiosity Index}

\begin{tabular}{lc}
\hline SCALE & PERCENT \\
\hline 0 Not Religious & $30.7 \%$ \\
1 & $21.3 \%$ \\
2 & $13.2 \%$ \\
3 Moderately Religious & $11.5 \%$ \\
4 & $7.8 \%$ \\
5 & $8.6 \%$ \\
6 Highly Religious & $6.8 \%$
\end{tabular}

\section{Cronbach's alpha $=.799$}

This output illustrates that almost one-third of individuals in the sample are not religious according to this definition of religiosity. Roughly 31 percent of the national population does not satisfy one condition in this index. This is not surprising considering the fact that I have made somewhat conservative requirements for religiosity. On a different note, approximately seven percent of participants in this survey would be classified as highly religious according to my definition.

\section{$\underline{\text { Paranormal Belief }}$}

Two sections of questions measuring paranormal belief were utilized in my analysis with one measuring religious paranormal beliefs and the other section measuring belief in the nonreligious paranormal. Questions on the religious paranormal are measured on a 4-point scale 
(absolutely, probably, probably not, absolutely not). Again, dummy variables were created, and items were coded in a manner where only positive answers (agree or absolutely agree) were counted in the analysis. Table 3A includes descriptive statistics illustrating belief in the religious paranormal according to the dummy variables created for these items.

\section{Table 3A: Percentages for Religious Paranormal Belief Items}

(Percentages reflect those individuals who responded "absolutely" or "probably". This question is worded exactly as in the original Baylor survey booklet.)

\begin{tabular}{lc}
\hline \multicolumn{1}{c}{ ITEMS } & PERCEN \\
\hline In your opinion, does each of the following exist? & \\
God & $88 \%$ \\
Satan & $73 \%$ \\
Heaven & $82 \%$ \\
Hell & $71 \%$ \\
Purgatory & $41 \%$ \\
Angels & $80 \%$ \\
Demons & $66 \%$ \\
Armageddon & $53 \%$ \\
The Rapture & $49 \%$ \\
Ghosts & $46 \%$
\end{tabular}

An index was also created for these beliefs which can be found in Appendix C. Together, these ten variables yield a Cronbach's alpha equal to $.896{ }^{4}$ This alpha value is in fact the highest among the indices created for this analysis. As you will see, this value is considerably higher than the alpha value for the index assessing non-religious paranormal belief.

\footnotetext{
${ }^{4}$ In appendix C you will see that the potential accuracy of this index could be increased to .915 with the exclusion of the variable assessing belief in the existence of ghosts. Although I would prefer to increase my alpha value, the difference in values is considerably small.
} 


\section{Table 3B: Percentages for Religious Paranormal Belief Index}

\begin{tabular}{lc}
\hline SCALE & PERCENT \\
\hline 0 No Belief & $8.8 \%$ \\
1 & $4.6 \%$ \\
2 & $3.2 \%$ \\
3 & $3.4 \%$ \\
4 & $4.5 \%$ \\
5 Moderate Belief & $3.4 \%$ \\
6 & $5.1 \%$ \\
7 & $10.1 \%$ \\
8 & $21.4 \%$ \\
9 & $16.9 \%$ \\
10 Strong Belief & $18.5 \%$
\end{tabular}

\section{Cronbach's Alpha $=.896$}

Table 3B contains percentage scores for the religious paranormal belief index. According to this table, about 21 percent of the population accepts belief in eight different types of religious paranormal phenomena. Although this index leaves me unable to identify the eight beliefs specifically, it does provide us with enough information to see that the majority of Americans hold many religious beliefs. This may or may not be the direct result of these types of beliefs being more socially acceptable in mainstream society.

Questions concerning belief in the non-religious paranormal are similar in format; however they are measured using a 5 point Lickert scale which includes an "undecided" category for respondents to choose from. As with the religious paranormal beliefs, these variables were also created into dummies so that a positive response (strongly agree or agree) were labeled 1 and all other responses as 0 . Located below are descriptive statistics for the non-religious paranormal belief items. 


\section{Table 4A: Percentages for Non-Religious Paranormal Belief Items}

(Percentages reflect those individuals who responded "strongly agree" or "agree" Items are worded as in the original Baylor Survey Booklet.)

\section{ITEMS}

To what extent do you agree or disagree with the following statements.

Ancient civilizations such as Atlantis once existed

Some alternative treatments are at least as effective as traditional medicine.

It is possible to influence the physical world through the mind alone.

Astrologers, palm-readers, tarot card readers, fortunetellers, and psychics can foresee the future

Astrology impacts one’s life and personality.

It is possible to communicate with the dead.

Places can be haunted.

Dreams sometimes foretell the future or reveal hidden truths.

Some UFOs are probably spaceships from other worlds.

Creatures such as Bigfoot and the Loch Ness Monster will one day be discovered by science

\section{PERCENT}

$41 \%$

$74 \%$

$28 \%$

$13 \%$

$14 \%$

$20 \%$

$37 \%$

$52 \%$

$25 \%$

$18 \%$

Appendix D contains the statistics for the index assessing belief in the non-religious paranormal. As with the religious paranormal index, ten items were entered yielding a Cronbach’s alpha of .781. As you can see, the alpha value is significantly smaller than that of the religious paranormal group. ${ }^{5}$

\footnotetext{
${ }^{5}$ For purposes of satisfying curiosity, I decided to run a reliability analysis in order to discover if including the variables for assessing belief in ghosts would have a significant impact on the index as a whole. With the inclusion of this variable, the alpha value increases to .801. While it may seem tempting again to include belief in the existence of ghosts in the category of non-religious paranormal beliefs, it will remain a part of the religious paranormal.
} 


\section{Table 4B: Percentages for Non-Religious Paranormal Belief Index}

\begin{tabular}{lc}
\hline SCALE & PERCENT \\
\hline 0 No Belief & $10 \%$ \\
1 & $15.6 \%$ \\
2 & $18.9 \%$ \\
3 & $12.5 \%$ \\
4 & $12.4 \%$ \\
5 Moderate Belief & $10.7 \%$ \\
6 & $7.2 \%$ \\
7 & $4.9 \%$ \\
8 & $3.1 \%$ \\
9 & $2.6 \%$ \\
10 Strong Belief & $2.2 \%$
\end{tabular}

\section{Cronbach's Alpha $=.781$}

As I stated earlier, there is a significant difference between the average amount of religious beliefs when compared to non-religious paranormal beliefs. Table 4B illustrates that the majority of Americans (approximately 19\%) believe in two of the ten non-religious paranormal belief items. Again, this may be the result of the stigma that is attached to these particular beliefs. On the other end of the spectrum, we see that only about 2 percent of the population professes belief in all ten of the non-religious paranormal phenomena.

\section{RESULTS}

Ordinary least squares regression was used in this analysis in order to evaluate the predictive power of religiosity and demographic variables on both religious and non-religious paranormal beliefs. Preliminary analyses were conducted to ensure no violation of the assumptions of normality, linearity, mulitcollinearity, and homoscedasticity. Table 5 presents two models in which the dependent variable is belief in religious paranormal phenomena. In Model 1, I control for demographic variables as well as those individuals who identify as religious "nones" explaining about $37 \%$ of the variance in the dependent variable. Not 


\section{TABLE 5 OLS Regression Predicting Religious Paranormal Belief}

(Standardized Coefficient in Parentheses)

\begin{tabular}{lrr}
\hline VARIABLES & MODEL 1 & MODEL 2 \\
\hline Intercept & \multicolumn{1}{c}{$10.547^{* * *}$} & \multicolumn{1}{c}{$7.972^{* * *}$} \\
Age & $-.343^{* * *}(-.101)$ & $-.268^{* * *}(-.079)$ \\
Female & $.554^{* * *}(.086)$ & $.223(.035)$ \\
White & $-.1 .085^{* * *}(-.116)$ & $-.764^{* * *}(-.081)$ \\
Education & $-.234^{* * *}(-.114)$ & $-.203^{* * *}(-.099)$ \\
Income & $-.267^{* * *}(-.112)$ & $-.178^{* *}(-.075)$ \\
Unemployed & $-.084(-.012)$ & $.002(.000)$ \\
Religious “Nones” & $-5.626^{* * *}(-.542)$ & $-5.139^{* * *}(-.495)$ \\
Religiosity Index & & $.417^{* * *}(.251)$ \\
Non-Religious Paranormal Index & & $.287 * * *(.224)$ \\
R square & .373 & .445 \\
\hline
\end{tabular}

surprisingly, we see that religious nones are least likely to adopt religious paranormal beliefs. In fact, compared to those with some type of religious identity, belief in the religious paranormal is about 5.626 units lower. A closer look at this model also shows that all demographic variables agree with the marginalization hypothesis except for the variable for unemployment which is the only demographic measure which was not significant within the model. We see that for every one unit increase on the scale for age, individuals profess about .343 units of religious belief. Females also profess about .554 more units of religious belief compared to males. Those who identify as white profess about 1.085 less units of religious belief. We also see that for every one unit increase on the education scale, belief in the religious paranormal drops .234 units. The same relationship applies with income; for every unit increase in income, belief in the religious paranormal drops .267 units.

In Model 2, two additional variables measuring religiosity and non-religious paranormal beliefs were controlled for explaining about $45 \%$ of the variance in the dependent variable. Religious "nones" again profess about 5.139 less religious beliefs than individuals with some religious identity. As within the first model, significant support is given for the marginalization 
argument. We see for every unit increase on the scale for age, belief in the religious paranormal decreases .268 units. A negative relationship also applies for our variables for gender, education, and income. Respondents who identify as white hold about .764 less units of religious beliefs compared to minority groups. For every unit increase in education, religious belief decreases .203 units whereas every unit increase in income results in a decrease of .178 units of religious paranormal belief.

With the inclusion of the religiosity and non-religious paranormal belief measures, we find that a positive relationship exists between these two variables and belief in religious paranormal phenomena. In other words, Model 2 lends support to the small-step hypothesis. More specifically, for every unit increase in non-religious paranormal belief, there is .287 unit increase in religious paranormal belief. In fact, next to being a religious none and highly religiosity, having strong belief in the non-religious paranormal is the third strongest predictor of religious paranormal belief (beta $=.287, \mathrm{p}<.001$ ). This is surprising since I controlled for those individuals who identify as highly religious. As was stated earlier, I tried to create a measure for religiosity that would separate individuals who were highly religious from those who were moderately or not religious. This model suggests however, that these individuals still hold beliefs which lie outside of mainstream religious teachings. 


\section{TABLE 6 OLS Regression Predicting Non-Religious Paranormal Belief}

(Standardized Coefficient in Parentheses)

\begin{tabular}{lcr}
\hline VARIABLES & MODEL 3 & MODEL 4 \\
\hline Intercept & \multicolumn{1}{c}{$5.579^{* * *}$} & $4.094^{* * *}$ \\
Age & $-.434^{* * *}(-.164)$ & $-.293^{* * *}(-.110)$ \\
Female & $.495^{* * *}(.098)$ & $.577^{* * *}(.115)$ \\
White & $-.575^{* *}(-.079)$ & $-.487^{* *}(-.067)$ \\
Education & $-.044(-.028)$ & $-.007(-.005)$ \\
Income & $-.159^{* *}(-.085)$ & $-.142^{* *}(-.077)$ \\
Unemployed & $.352^{*}(-.062)$ & $-.314^{*}(-.056)$ \\
Religious “Nones” & $-.113(-.014)$ & $.755^{* *}(.093)$ \\
Religiosity Index & & $-.481^{* * *}(-.371)$ \\
Religious Paranormal Index & & $.247 * * *(.317)$ \\
R square value & .063 & .214 \\
\hline
\end{tabular}

Table 6 presents the last of the regression models in this analysis which concentrate on measuring belief in the non-religious paranormal. Model 3 displays the demographic measures while controlling for the religious nones. The model as a whole explains about 6 percent of the variance compared to $37 \%$ and $45 \%$ percent within the first two models. There is also a large difference in our intercept values as compared to those in Models 1 and 2. Nevertheless, we find strong support for the marginalization theory. One unit increase in age results in a .434 unit decrease in non-religious paranormal beliefs. Females profess about .459 units of non-religious belief more when compared to males. Those who identify as white believe in about .575 less beliefs than compared to other racial identities. We also find that for every unit on the scale for income, non-religious paranormal belief decreases by .159 units. In addition, individuals who are unemployed profess about .352 less non-religious paranormal beliefs compared to individuals who hold some form of employment (paid work or working without pay in a family business or farm).

This model also specifies a negative relationship between having no religion and belief in the non-religious paranormal which contradicts previous research suggesting that religious 
“nones" are more likely to adopt non-religious paranormal claims in place of religious paranormal beliefs (Emmons and Sobal 1981). In fact, it is not even significant within the model. This is somewhat surprising due to the fact of its significance within the religious paranormal belief models.

The final model includes the addition of the religiosity and religious paranormal belief variables. Together these measures account for about $21 \%$ of the variance explained in the dependent variable. Even though education remains insignificant, support for the marginalization theory remains. A unit increase in the age scale results in a .293 decrease in nonreligious belief. Females profess belief in about .577 more beliefs than males. White respondents accept about 487 less units of non-religious belief compared to other identities. Every unit increase in the income scale results in a .142 unit decrease in non-religious paranormal belief. Finally, individuals who are unemployed hold about .314 less non-religious beliefs than those who are employed.

Upon examining the model more closely, we find that individuals who identify as religious "nones" are more likely than individuals with some religious identity to believe in the nonreligious paranormal. That is, they hold about .755 more units of non-religious paranormal belief. This finding supports the work of Emmons and Sobal (1981) yet contradicts work by Orenstein (2002) or Mencken et al (2009).

Another interesting finding within this model lends more support for the argument of a small step between belief systems. As we saw within Model 2, a positive relationship exists between both types of paranormal beliefs, for in this model we see that those individuals who profess strong belief in the religious paranormal are significantly more likely to also believe in the non-religious paranormal. In fact, for each unit increase in religious paranormal belief, there is a .247 unit increase in non-religious belief. In addition, this variable has the second strongest effect (beta $=.317 ; \mathrm{p}<.001$ ) on non-religious paranormal belief as it was also in Model 2 and once again provides evidence supporting the small step theory.

\section{DISCUSSION}

A total of five hypotheses were tested in thesis. In my first hypothesis, I predicted that high "religiosity" would be positively associated with belief in the religious paranormal group and negatively with belief in the non-religious paranormal. Models 2 and 4 support this claim showing that religiosity is a positive predictor for religious paranormal belief and a negative 
predictor for non-religious paranormal belie. Aarino and Lindeman (2007) suggest a simple and somewhat obvious solution claiming highly religious adhere more closely to their religious doctrines are therefore less likely to adopt these beliefs. In essence, religiosity acts as a shell blocking out anything threatening the individual's beliefs and values.

Aarino and Lindeman's argument for why the highly religious avoid these beliefs is similar to my view on this matter. It seems almost obvious that individuals who practice their religion frequently and hold their faith sacred would remain distant from non-religious paranormal beliefs. In examining the literature, I noticed that most studies did not employ very many variables capturing individual religiosity which prompted me to include a more comprehensive religiosity variable in this analysis. It is a possibility that previous studies have underestimated or overlooked the predictive power of religiosity. In an attempt to gain a better understanding of this predictive power, my second hypothesis suggested religiosity to have the strongest influence on both types of paranormal beliefs. This hypothesis was only supported in regards to nonreligious paranormal beliefs (beta $=-.371 ; \mathrm{p}<.001$ ). Although this relationship was not supported within Model 2 measuring its effect on belief in the religious paranormal, it had the second strongest effect (beta $=-.251 ; \mathrm{p}<.001$ ) next to being a religious "none" (beta $=-.495 ; \mathrm{p}<$ $.001)$.

Based on previous literature from Emmons and Sobal (1981), I hypothesized that religious "nones” would be more likely to hold non-religious paranormal beliefs. This relationship was indeed supported, however it only occurred when controlling for religiosity and belief in the religious paranormal. What this means then, is that demographic variables alone are not accurate predictors for explaining why individuals adopt alternative beliefs. Religiosity and belief in the religious paranormal are in fact more accurate at assessing this argument.

Hypothesis four is a direct test of the marginality hypothesis suggesting that paranormal beliefs are held by those who are marginalized from the rest of society based on SES, race, sex, education, income, and other indicators of status. This argument was supported within both models measuring non-religious paranormal belief. According to Models 3 and 4, non-religious paranormal belief is associated with being older, female, non-white, less educated, having a lower annual income, and being currently unemployed. All variables were significant within these models with the exception of education, and while this was true, the direction of the 
relationship to non-religious paranormal belief coincides with the marginalization argument, just as all other remaining demographic variables do.

Because some beliefs are deemed more socially acceptable in society, I did not expect the marginalization theory to apply to religious paranormal beliefs. In other words, these beliefs are “less risky” for individuals of higher status to accept because they are a part of mainstream society. Although the relationship was not expected, I found similar support for the marginalization argument. However, there are some significant differences in these models when compared to those measuring belief in the non-religious paranormal. Education was significant $(\mathrm{p}<.001)$ in Model 1 and 2, yet insignificant in Models 3 and 4. Within either model, unemployment failed to be a significant factor. Also, when controlling for religiosity and belief in the non-religious paranormal, being a female has no significant effect on religious paranormal belief. This is surprising because we would expect for females to be more likely to accept more religious beliefs given they are more religious as suggested by the literature. However, Model 2 does not support this claim and is therefore contradictory to Mears and Ellison (2000) which suggests that women are not only more religious than men, but also more spiritual as well.

My final hypothesis tested the small step theory suggesting a positive relationship between religious and non-religious paranormal beliefs. Originally, I predicted for there to be a negative relationship between the two based on the fact that I controlled for those individuals who identify as highly religious as well as those who did not identify with any formal religion (“nones”). However, even when controlling for these factors, strong support for the small step argument is provided. That is, belief in one type of paranormal can predict belief in another.

\section{LIMITATIONS}

The scientific study of paranormal belief is complex and diverse which has prevented researchers from forming consistent explanations as to what factors are significant in explaining belief in the paranormal. The crux of the problem more than likely exists within the manner in which one defines the paranormal. That is, support for specific theories may be contingent on the researcher(s) opinion about what types of beliefs belong fit a particular category. In my research, I have categorized the paranormal according to phenomena that can be found within religious texts. Sullivan (1982) categorized the paranormal into groups with the first group being general superstitious belief which included belief in ESP, astrology, UFO’s, hauntings, and Tarot 
cards. The second group, labeled orthogonal religious factors, contained items on belief in God, evolution, and demonic possession. Mencken et al (2009) divided the paranormal into two categories: conventional Christian beliefs and “New Age” paranormal beliefs. Sobal and Emmons (1982) established three separate groups which included belief in psychic phenomena, religious beliefs, and the belief in “other beings” such as Bigfoot. According to Tobacyk's Paranormal Belief scale, there are seven different subscales of the paranormal (traditional religious belief, psi belief, witchcraft, superstition, spiritualism, extraordinary life forms, and precognition). It is quite apparent that researchers certainly do not agree on the paranormal in terms of how it should be defined or measured.

Each one of the previously mentioned research projects yielded results different from one another. The conclusions drawn from these studies may be based largely on how the researcher(s) categorized the paranormal. Yes, weak samples have caused much of the confusion within this type of research, but it may not be the problem entirely. Researchers are now starting to realize the multi-dimensionality of paranormal beliefs. Until general measures can be agreed upon, it seems that research in this area will continue to yield contradictory results.

Surveys such as this are an essential tool when searching for large sample data in order to make conclusions to be drawn to a general population. However, surveys can have their shortcomings. In regards to this particular survey, some researchers would argue that the quality of data in surveys on the paranormal can depend largely upon how researchers define the paranormal. Others contest that the simple format of surveys can impact how respondents acknowledge paranormal beliefs. Gray (1990) found that respondents report less belief in paranormal phenomena when they are asked to simply check an option on the degree to which they believe in something. Considering the Baylor Survey is devised with several checklists, this is an important idea to keep in mind.

Other researchers would question the inclusion of “don’t know” or “uncertain” response options in a survey on paranormal belief. Grey (1988) argues that when participants are forced to declare belief or disbelief, the level of either response can be magnified. Should these types of surveys include a category for indecisiveness for phenomena that are so controversial in terms of their existence? One cannot help but wonder about how much or how little of an effect the inclusion of this category can influence a respondent's answer as well as the overall results of the analyses. The Baylor Survey is devised in a manner which includes a category for individuals 
who are undecided in their belief. However, this choice is only available within the items measuring non-religious paranormal belief. It would be interesting to see what the data would look like if both the religious and non-religious paranormal belief items contained a category for those individuals who are "undecided." Similarly, it would be just as interesting to see the data with both sections excluding this choice.

Using secondary data to complete this thesis has saved an immense amount of time, money, and effort. However, despite its benefits, utilizing secondary data can have its drawbacks (Freese 2007). Even with the amount of work involved in designing and collecting the data, surveys can only provide indirect insight on the processes of an individual's social life. Although the data are better in quality when compared to other projects assessing belief in the paranormal, it is important to keep in mind that the results are neither conclusive nor absolute.

Creating indices has allowed me to utilize more comprehensive measures for assessing religiosity and paranormal belief. However, unlike other studies I am unable to establish which types of paranormal, both religious and non-religious, are associated with certain variables. For example, I cannot say that weak church attendance is associated with strong belief in astrology or that individuals who interpret the Bible literally word-for-word are less likely to believe in UFOs. In creating these large indices, I am limited in the specificity in the conclusions I am able to draw.

\section{CONCLUSION}

This research sought to better explain paranormal belief using data that are regarded by some as the best religious survey data that exist. Additional support was given to the marginalization and small step hypothesis, however, more research needs to be performed before any concrete assumptions can be made. The main problem that I see within this research is the lack of consistency with measuring the paranormal. Depending on which author you read, you will find a significant difference in the way each one defines or categorizes the paranormal (e.g. Orenstein 2002 vs. Rice 2003). Each researcher defines the paranormal according to what he or she believes is right. Yes, there are those paranormal assessment tools used more than once in research such as Tobacyk's paranormal scale. However, even with this scale we have yet another way of defining the paranormal. How are researchers supposed to come to any conclusions or agreement if they continue to measure the paranormal differently? 
It is imperative that researchers agree on some convention for measuring the paranormal. It does not take long for someone to realize just how difficult this can be. There are numerous types of phenomena which could be classified as paranormal such as UFOs, Bigfoot, or ghosts. On the other hand, there are those phenomena which are less clear. The Baylor survey, for instance, contains an item on alternative medicines. Because this term is so broad, it can be argued if it should even be classified as being paranormal or not. Various concepts can be classified as alternative medicine such as acupuncture, spiritual healing, or using vitamins, minerals, or other substances to alleviate some form of illness. Certainly spiritual healing could be considered paranormal, but what can be said of the other concepts? Should they be considered paranormal? Why or why not?

I strongly believe that qualitative research could assist greatly in helping form a standard definition of the paranormal. Interviews could give us insight as to what the paranormal should entail. That is, instead of researchers telling society what phenomena are paranormal; why not allow society to tell us what is paranormal? Aside from this, a respondent's testimony may also provide us with a better measure of the intensity of one's belief in a particular type of phenomena instead of asking participants to simply check a box marked yes or no. Even though larges samples sizes would be difficult to attain, I believe qualitative research could at least help guide us in the right direction of formulating some convention for defining and assessing belief in the paranormal.

Even though many contradictions exist throughout the literature on paranormal belief, researchers must not be discouraged. Researchers should realize that all people may not believe in the paranormal the same way (Goode 2000). For example, Bader, Baker, and Mencken (2008) studied a particular subset of society; those who believe that believe there is a spiritual war occurring between God and the devil. Their findings suggest a positive relationship between evil forces (Satan, demons, Armageddon) and non-Christian paranormal phenomena such as haunted houses and UFOs. In this case, one could conclude that indeed the small step argument is effective in predicting belief. That is, they may believe in both Christian and non-Christian paranormal phenomena, yet they avoid them because they view them as Satanic or the work of the devil. However, can we say that this concept works for all types of believers? It is important for researchers to understand the difference between different sets of believers. Previous 
research may be valid in some sense. That is, findings may be valid for a particular subset of individuals.

My findings suggest that religious individuals hold beliefs which are outside of conventional church dogma. It seems as if those who identify as highly religious may not be as rigid as previously thought. One would expect for highly religious individuals to reject beliefs which could challenge or threaten their religion or religiosity. Such is not the case in this thesis. The question then is: why does this relationship exist? Is it because they believe these phenomena to be the work of the devil as suggested in previous research or is it something else? That something else may have something to do with the marginalization argument. More specifically, it is quite possible for respondents who identify as highly religious to be marginalized from society through a low annual income, poor educational background, etc. In essence, marginalization theory could also be applied for those individuals who have strong ties to the church. Unfortunately, this analysis does not allow for me to investigate this idea. Still, it is an interesting argument and could be another reason why my models support the small step theory.

No matter what the case may be, it is important to understand why the highly religious accept belief in these phenomena. More research needs to be done in an effort to discover whether or not these beliefs are being avoided or not. As mentioned in a previous paragraph, Mencken, Bader, and Stark (2008) discovered that firm believers in Christianity are just as likely as those who are not to experiment with the paranormal. They also found that individuals who held conventional Christian beliefs but did not attend church were the most likely to participate in paranormal activities. These researchers suggest that this relationship exists due to the individual's lack of church attendance. It is church attendance, they believe, which places the individual under great social control. By attending church, individuals who hold strong Christian beliefs are frequently exposed to others who share similar beliefs and ideas. As a result, these individuals are least likely to engage in activities which are at odds with conventional Christian beliefs.

Researchers must recognize the importance of religious participation and religiosity in understanding belief in the paranormal. The point that Mencken, Bader, and Stark (2008) make should not be underestimated. Actively participating in the church and observing its teachings does in fact place the actor under social control. Future research should utilize more variables assessing religiosity in order to obtain a more accurate indicator of this concept. In regards to 
this research, higher religiosity is associated with lower levels of non-religious paranormal belief. In fact, religiosity had the strongest effect on non-religious paranormal belief compared to all other variables within the model. I firmly believe that future research can verify similar results on religiosity. Much of the confusion caused in previous literature may stem from poor sample sizes or weak indicators of religiosity (e.g. only using church attendance).

It is vital that researchers persevere in their quest for establishing the predictors of paranormal belief. This research can benefit the most using some standard for measuring belief as well as using sample data which can be generalized to a large population. By and large, the world of the paranormal is difficult to assess from the perspective of a social scientist. Numerous variables effect individual belief. Unfortunately, researchers are only able to give some insight to understanding this concept. This thesis, along with other research published using this data set, will hopefully put us on the right path to better explaining how individuals come to accept belief in the paranormal. 


\section{APPENDIX A \\ Paranormal Television Shows Aired Since 2001}

$\underline{2001}$

- Scariest Places on Earth Syfy

$\underline{2003}$

- Dead Like Me Syfy

2004

- Ghost Hunters Syfy

$\underline{2005}$

- Medium CBS

- Ghostly Encounters Bio

- Supernatural CW

- Ghost Whisperer Syfy

- A Haunting Discovery

2006

- Psych USA

$\underline{2007}$

- Destination Truth Syfy

- Paranormal State A\&E

- Psychic Kids A\&E

- Monsterquest History

$\underline{2008}$

- UFO Hunters History

- Fringe FOX

- Ghost Hunters International Syfy

- Ghost Adventures Travel

$\underline{2009}$

- Mysteryquest History

- Ghost Lab Discovery

- Paranormal Cops A\&E

- Ghost Hunters Academy Syfy

$\underline{2010}$

- Past Life FOX 


\section{APPENDIX B}

\section{Index for Religiosity}

Church attendance

Praying outside normal .784

worship hours

How often you read the Bible,

Koran, or Torah

Saying grace at meals

How often you attend

Bible Study or Sunday School

Biblical literalism

Cronbach's alpha $=.799$ 


\section{APPENDIX C}

Index for Religious Paranormal Beliefs

VARIABLE

God

Satan

Heaven

Hell

Purgatory

Angels

Demons

Armageddon

The Rapture

Ghosts
ALPHA IF ITEM DELETED

.886

.874

.879

.873

.899

.877

.877

.885

.887

.915

Cronbach's alpha $=.896$ 


\section{APPENDIX D}

\section{Index for Non-Religious Paranormal Beliefs}

To what extent do you agree or disagree with the following statements.

Ancient civilizations such as Atlantis once existed $\quad .767$

Some alternative treatments are at least as effective as traditional $\quad .786$

medicine.

It is possible to influence the physical world through the mind alone. $\quad .765$

Astrologers, palm-readers, tarot card readers, fortunetellers, and $\quad .757$

psychics can foresee the future

Astrology impacts one’s life and personality. $\quad .764$

$\begin{array}{ll}\text { It is possible to communicate with the dead. } & .749\end{array}$

Places can be haunted. $\quad .744$

Dreams sometimes foretell the future or reveal hidden truths. $\quad .762$

Some UFOs are probably spaceships from other worlds. $\quad .761$

Creatures such as Bigfoot and the Loch Ness Monster will one day $\quad .767$

be discovered by science

Cronbach's alpha $=.781$ 


\section{REFERENCES}

Alcock, James E. 1981. “Parapsychology: Science or magic?” Oxford: Pergamon Press.

Aarino, Kia and Marjanna Lindeman. 2007. "Religious People and Paranormal Believers. Alike or Different?” Journal of Individual Differences 28(1): 1-9.

Bainbrigde, William S. and Rodney Stark. 1980. "The Consciousness Reformation Reconsidered.” Journal for the Scientific Study of Religion 20: 1-16.

Berger, Peter L., and Thomas Luckmann. 1966. The Social Construction of Reality: A Treatise in the Sociology of Knowledge. Garden City, New York: Doubleday.

Clarke, David. 1991. "Belief in the Paranormal: A New Zealand Survey." Journal for the Society of Psychical Research 57: 412-425.

Donahue, Michael J. 1993. "Prevalence and Correlates of New Age Beliefs in Six Protestant Denominations.” Journal for the Scientific Study of Religion 32(2): 177-184.

Emmons, Charles F. and Jeff Sobal. 1981. "Paranormal Beliefs: Functional Alternatives to Mainstream Religion?” Review of Religious Research 22: 301-312.

Freese, Jeremy. 2007. "Secondary Analysis of Large Social Surveys.” Department of Sociology, University of Wisconsin, Madison, WI. Unpublished manuscript.

Fox, John W. 1992. "The Structure, Stability, and Social Antecedents of Reported Paranormal Experiences." Sociological Analysis 53:417-431.

Glendinning, Tony. 2006. "Religious Involvement, Conventional Christian, and Unconventional Nonmaterialist Belief.” Journal for the Scientific Study of Religion 45: 585-595.

Greeley, Andrew M. 1975. The Sociology of the Paranormal: A Reconnaissance. Beverly Hills, CA: Sage Publications.

Grey, William. 1988. “Australia’s Credulity Rating: Bad or Worse?” The Skeptic 8:35.

Hirschi, Travis. 1969. Causes of Delinquency. Berkley, California: University of California Press.

Irwin, Harvey J. 1993. "Belief in the Paranormal: A Review of the Empirical Literature.” Journal for the American Society of Psychical Research 87: 1-39.

Irwin, Harvey J. 1985. "A Study of the Measurement and the Correlates of Paranormal Belief." Journal for the American Society of Psychical Research 79: 301-326.

MacDonald, William L. 1995. "The Effects of Religiosity and Structural Strain on Reported Paranormal Experiences.” Journal for the Scientific Study of Religion 34: 366-376.

Mears, Daniel P., and Christopher G. Ellison. 2000. "Who Buys New Age Materials? Exploring Sociodemographic, Religious, Network, and Contextual Correlates of New Age Consumption. Sociology of Religion 61(3): 289-314.

Mencken, Carson., Christopher D. Bader, and Ye Jung Kim. 2009. "Round Trip to Hell in a Flying Saucer: The Relationship between Conventional Christian and Paranormal Beliefs in the United States.” Sociology of Religion. 0:0 1-24. 
Mencken, Carson, Christopher D. Bader, and Rodney Stark. 2008. “Conventional Christian Beliefs and Experimentation with the Paranormal.” Review of Religious Research 50(2): 194-205.

McKinnon, Andrew M. 2003. “The Religious, the Paranormal, and Church Attendance: A Response to Orenstein.” Journal for the Scientific Study of Religion 42: 299-303.

Moore, David W. 2005. “Three in Four Americans Believe in Paranormal.” The Gallup Poll

Orenstein, Alan. 2002. "Religion and Paranormal Belief.” Journal for the Scientific Study of Religion 41: 301-311.

Peltzer, Karl. 2003. "Magical thinking and paranormal beliefs among secondary and university student in South Africa.” Personality and Individual Differences 35: 1419-1426.

Rice, Tom W. 2003. "Believe it or Not: Religious and Other Paranormal Beliefs in the United States.” Journal for the Scientific Study of Religion 42: 95-106.

Sheils, David and Paul Berg. (1977). "A Research Note on Sociological Variables Related to Belief in Psychic Phenomena.” Wisconsin Sociologist 14: 24-31.

Smith, Christian 1998. American Evangelicalism Embattled and Thriving. University of Chicago Press. Chicago, IL

Sparks, Glen G., Cheri W. Sparks, and Kristen Gray. 1995. "Media impact on fright reactions and belief in UFOs: The potential role of mental imagery. Communication Research 22: 3-23.

Sparks, Glen G., C. Leigh Nelson, and Rose G. Campbell. 1997. “The relationship between exposure to televised messages about paranormal phenomena and paranormal beliefs." Journal of Broadcasting and Electronic Media 41: 345-359.

Stark, Rodney and William S. Bainbridge. 1980. "Towards a Theory of Religion: Religious Commitment.” Journal for the Scientific Study of Religion. 19: 114-128.

Stark, Rodney and William S. Bainbridge. 1985. The Future of Religion: Secularization, Revival and Cult Formation. Berkley, California: University of California Press.

Sullivan, Clyde. 1982. “On Patterns of Religious, Psychic, and Other Paranormal Phenomena.” Zetetic Scholar 10: 147-149.

Tam, Wai-Chong, and Yung-Jong Shiah. 2004. "Paranormal Belief, Religiosity, and Cognitive Complexity.” The Parapsychological Convention. 423-429.

Thalbourne, Michael A. 1982. "Some Correlates of Belief in Psychical Phenomena: A Partial Replication of the Haraldsson Findings.” Parapsychology Review 15: 13-15.

Tobacyk, Jerome and Gary Milford. 1983. "Belief in Paranormal Phenomena: Assessment, Instrument Development, and Implications for Personality Functioning.” Journal of Personality and Social Psychology 44: 1029-1037. 